\title{
Differences in Plasma MMPs and TIMPs Protein Expression and Chemotherapy Response in Patients with Tobacco- or Wood-Smoke-Induced Lung Cancer
}

\author{
Georgina Gonzalez-Avila Javier Delgado Daniel A. Mendoza-Posada \\ Bettina Sommer Carlos Ramos Arnoldo Aquino-Galvez Catalina Camacho \\ Laboratorio de Oncología Biomédica, Departamento de Enfermedades Crónico Degenerativas, Instituto Nacional de \\ Enfermedades Respiratorias 'Ismael Cosio Villegas', México, México
}

\section{Key Words}

Gelatinase activity $\cdot$ Lung cancer $\cdot$ Matrix

metalloproteinases $\cdot$ Never-smokers $\cdot$ Tissue inhibitors of

matrix metalloproteinases $\cdot$ Wood smoke

\begin{abstract}
Background: One of the risk factors associated with lung cancer in never-smoker patients is wood smoke exposure (WS). However, information about its clinical and molecular characteristics remains scant. Objective: This was to analyze - in plasma from patients with tobacco- or woodsmoke-induced lung cancer - whether the enzymatic activity and concentration of matrix metalloproteinases (MMPs) and tissue inhibitors of matrix metalloproteinases (TIMPs) differ, and to determine whether there was a correlation between these indicators of the metastatic potential and the first-line chemotherapy response. Methods: Patients were classified according to lung cancer associated with: the smoking of tobacco $(\mathrm{T})$, WS and where no association with a known risk factor $(\mathrm{N})$ could be established. The gelatinase activity of plasma MMP was analyzed by radiolabeled substrate degradation and zymography assay. Protein expression of MMPs and TIMPs was evaluated by Western blot densitometry analysis. Results: The $26.9 \%$ WS patients had a better response to therapy in comparison with the $T$ group $(\mathrm{OR}=4.9,95 \% \mathrm{Cl}=$
\end{abstract}

$1.25-20.15 ; p=0.019)$. The lowest gelatinase activity was observed in WS subjects, in comparison with $\mathrm{T}$ and $\mathrm{N}$ subjects $(96.7 \pm 15.9,182.9 \pm 31.5$ and $163.3 \pm 22.7 \mu \mathrm{g}$ of degraded gelatin/mg of incubated plasma protein, respectively; $p<$ $0.025)$; this enzymatic activity corresponded to MMP-2. The highest MMP-2, MMP-9, MT1-MMP and TIMP-1 plasma levels were observed in T subjects. Conclusion: Tobacco and wood smoke have different effects on MMP and TIMP synthesis and gelatinase activity, directly influencing lung cancer metastatic potential and chemotherapy response.

Copyright $\odot 2012$ S. Karger AG, Base

\section{Introduction}

Tobacco has been considered the main risk factor in lung cancer pathogenesis. However, statistics show that $15 \%$ of men and $53 \%$ of women with lung cancer are never-smokers [1]. In recent years, epidemiological studies have identified several etiological factors that could be involved in lung cancer onset in never-smokers, such as exposure to radon, coal smoke, wood smoke or asbestos, as well as genetic, hormonal and viral factors $[2,3]$.

In developing countries, wood, dung and charcoal (defined as 'biomass fuel') are burned and used as low-cost fuel sources for cooking, heating and lighting [4]. The use

\section{KARGER}

Fax +4161306 1234

E-Mail karger@karger.com

www.karger.com (c) 2012 S. Karger AG, Basel

$0025-7931 / 13 / 0854-0281 \$ 38.00 / 0$

Accessible online at:

www.karger.com/res
Georgina González-Avila, MD, PhD, Laboratorio de Oncología Biomédica Departamento de Enfermedades Crónico Degenerativas Instituto Nacional de Enfermedades Respiratorias 'Ismael Cosio Villegas Calzada de Tlalpan 4502, CP 14080, México, D.F. (México)

Tel. +52 555487 1700, ext. 5287, E-Mail ggonzalezavila@yahoo.com 
of wood as fuel, particularly in rural areas, could be a potential risk factor for lung cancer, but the evidence confirming that wood smoke induces lung cancer is still not enough $[5,6]$. Nevertheless, the International Agency for Research on Cancer concluded that biomass smoke (mainly wood) is 'probably carcinogenic to humans (Group 2A)' on the basis of the studies that demonstrated molecular and cytogenetic effects in humans and in experimental animals [7]. These effects could be due to wood smoke composition that includes carcinogenic molecules such as formaldehyde, benzene, benzo(a)anthracene, benzofluoranthenes, benzo(a)pyrene, chromium, nickel and chlorinated dioxins; all of them have been implicated in lung cancer pathogenesis [8].

In general terms, lung cancer in never-smokers has a different profile from that of tobacco smokers. It affects women more frequently, it shows a major incidence at a younger age, adenocarcinoma is the predominant reported histologic subtype and never-smoker patients have a better response to targeted therapy [9]. Although knowledge about lung cancer in never-smokers has substantially increased, studies evaluating the metastatic potential of this cancer are not yet available. Definition of lung cancer aggressiveness might help in treatment onset, as it is known that lung cancer in never-smokers is diagnosed at a more advanced stage compared to tobacco-smoking patients $[9,10]$.

In this context, several components of the extracellular matrix (ECM) are modified during the metastatic process by the matrix metalloproteinases (MMPs), a family of calcium-zinc-dependent endopeptidases [11-13]. These enzymes are synthesized as zymogens and require cleavage of the amino-terminal domain for their activation. Based on their substrate specificity, MMPs are grouped into collagenases, gelatinases, stromelysins and membrane-type MMPs (MT-MMPs). Two of them, MMP-2 and MMP-9 (gelatinases), have often been associated with the invasive potential of neoplastic cells and the aggressiveness of cancer. MMP enzymatic activity is regulated by a group of 4 specific inhibitors, the tissue inhibitors of metalloproteinases (TIMPs) that bind to the active forms of these enzymes, forming tight 1:1 stoichiometric complexes [14].

On the other hand, never-smoker patients with lung cancer at advanced stages are treated as tobacco smokers with standard first-line chemotherapy (cisplatin and a third-generation drug) or second-line treatment (docetaxel and pemetrexed) $[15,16]$. In some health centers, never-smokers' second-line treatment consists of the use of targeted therapy (erlotinib and gefitinib) and good re- sponses have been observed [17]. However, targeted therapy in developing countries is too expensive; therefore, conventional chemotherapy is used more often, even though information concerning response to platin-based therapy in never-smoker lung cancer is scarce $[18,19]$.

Since lung cancer pathogenesis, tumor biology and clinical features are different among smoker and neversmoker patients, it is conceivable to postulate that differences in lung cancer metastatic potential and in the response to cisplatin first-line chemotherapy might also exist. Therefore, the aim of this study was to analyze whether the gelatinase activity of plasma MMP-2 and MMP-9 and the plasma concentrations of MMP-2, MMP9, MT1-MMP, TIMP-1 and TIMP-2 in tobacco- and wood-smoke-induced lung cancer patients differ, and to determine whether these indicators of the metastatic potential correlate with the cisplatin first-line chemotherapy response.

\section{Materials and Methods}

\section{Study Population}

Seventy-eight patients with primary lung adenocarcinoma were studied. They received follow-up for the duration of their first-line chemotherapy treatment. Only these 78 patients fulfilled the criteria for the variants we wanted to examine in this work, they were staged prior to chemotherapy according to Mountain [20].

According to risk factors, subjects were divided into the following groups: (1) lung cancer associated with wood smoke exposure (WS) consisting of patients who were never-smokers but had been exposed to domestic wood smoke for a mean duration of 35 \pm 22.5 years ( $232.35 \pm 41.3 \mathrm{~h} /$ year; range $30-816 \mathrm{~h} /$ year), (2) lung cancer associated with tobacco smoking $(\mathrm{T})$ including subjects who were current smokers $>10$ years $(30.6 \pm 13.9$ years $)$ with a mean smoking history of $24.82 \pm 5.2$ pack years (range $2.5-98$ pack years) and (3) a negative group $(\mathrm{N})$ that consisted of those patients with no history of tobacco, wood smoke, solvent, radon or asbestos exposure, nor a family history of lung cancer (table 1).

Each patient received 6 cycles of cisplatin alone $(\mathrm{n}=4 ; 70 \mathrm{mg} /$ $\mathrm{m}^{2}$ on day 1$)$ or in combination with paclitaxel $(\mathrm{n}=31 ; 200 \mathrm{mg} /$ $\mathrm{m}^{2}$ on day 1$)$, vinorelbine $\left(\mathrm{n}=22 ; 30 \mathrm{mg} / \mathrm{m}^{2}\right.$ on days 1 and 7$)$, gemcitabine $\left(\mathrm{n}=17 ; 1,250 \mathrm{mg} / \mathrm{m}^{2}\right.$ on days 1 and 8$)$ or docetaxel $(\mathrm{n}=$ $4 ; 75 \mathrm{mg} / \mathrm{m}^{2}$ on day 1 ). There was a 3 -week interval between each cycle. Chemotherapy was decided according to the economic status of each patient, taking into consideration that the standard treatment consists of cisplatin or carboplatin plus a third-generation drug [15]. The response to chemotherapy was evaluated according to the Response Evaluation Criteria in Solid Tumors (RECIST) guidelines: $\mathrm{CR}=$ complete response, $\mathrm{PR}=$ partial response, $\mathrm{PD}=$ progression of disease, $\mathrm{ORR}=$ overall response rate, i.e. $\mathrm{CR}+\mathrm{PR}[21]$.

Thirty-one healthy never-smoker volunteers without WS, with normal spirometry values, no signs of infective respiratory disease and no history of atopy, allergy or asthma were actively recruited as controls. 
Table 1. Clinical characteristics of lung adenocarcinoma patients

\begin{tabular}{llllc}
\hline $\begin{array}{l}\text { Character- } \\
\text { istics }\end{array}$ & $\begin{array}{l}\text { All } \\
\text { patients }\end{array}$ & WS & \multicolumn{2}{l}{ T } \\
\hline $\begin{array}{l}\text { Subjects } \\
\text { Gender }\end{array}$ & 78 & 27 & 24 & 27 \\
$\quad$ & & & \\
$\quad$ Women & 51 & $24 / 51$ & $10 / 51$ & $17 / 51$ \\
Age & $61.2 \pm 11.4$ & $63.7 \pm 11.8$ & $60.3 \pm 12.6$ & $57.7 \pm 9.5$ \\
Men & $34.6(27 / 78)$ & $11.1(3 / 27)$ & $51.9(14 / 27)$ & $37(10 / 27)$ \\
Age & $58.9 \pm 11.4$ & $57 \pm 22.6$ & $59.7 \pm 11.1$ & $58.2 \pm 10.9$ \\
Stage (TNM) & & & & \\
IIIA & $5 / 78$ & $2 / 5$ & $2 / 5$ & $1 / 5$ \\
IIIB & $16 / 78$ & $6 / 16$ & $5 / 16$ & $5 / 16$ \\
IV & $57 / 78$ & $19 / 57$ & $17 / 57$ & $21 / 57$ \\
\hline
\end{tabular}

Data are presented as number of studied patients/total patients. Age is expressed in years as mean $\pm \mathrm{SD}$.

Informed consent was obtained from each patient and the protocol was approved by the local Ethic and Research Committees.

Venous blood samples from healthy subjects and from lung cancer patients obtained prior to therapy were collected in 5-ml lithium heparin-coated tubes. Plasma protein amounts were measured by the bicinchoninic acid protein assay (Pierce Chemical Co., Rockford, Ill., USA) [22].

\section{Gelatinase Activity Assay}

Twenty micrograms of ${ }^{3} \mathrm{H}$-labeled heat-denatured type I collagen (gelatin) were incubated with $20 \mu \mathrm{g}$ of plasma protein from each subject and TNC buffer (50 mM Tris- $\mathrm{HCl}, 0.15 \mathrm{mM} \mathrm{NaCl}$, $20 \mathrm{mM} \mathrm{CaCl}_{2}$ and $0.02 \%$ sodium azide; $\mathrm{pH} 7.4$ ), with or without EDTA at $37^{\circ} \mathrm{C}$ for $24 \mathrm{~h} \mathrm{[23].} \mathrm{Labeled} \mathrm{gelatin} \mathrm{plus} \mathrm{collagenase} \mathrm{clos-}$ tridium and gelatin with TNC buffer were used as positive and negative controls. Gelatinase activity was limited to EDTA-inhibitable ${ }^{3} \mathrm{H}$-gelatin degradation. Results were expressed as micrograms of degraded gelatin per milligram of incubated plasma protein.

\section{Zymography Analysis}

Substrate gel electrophoresis was carried out in $8 \%$ SDS-PAGE gels containing $0.1 \%$ pig skin gelatin. Twenty micrograms of plasma protein from each sample were applied per lane under nondenaturating conditions. After electrophoresis, the gels were washed in $2.5 \%$ Triton $\mathrm{X}-100$ for $30 \mathrm{~min}$ and then incubated with TNC buffer at $37^{\circ} \mathrm{C}$ for $24 \mathrm{~h}$. Each gel was stained in $0.05 \%$ Coomassie blue G-250 and destained in 10\% methanol-10\% acetic acid. The gelatinase activity was visualized as transparent bands against a blue background on the stained SDS-PAGE gelatin gels. Bands detected in the zymography assay were analyzed by densitometry, using Kodak Digital Science ID Image Analysis software. Results were expressed as densitometry units (DU).

Western Blot Assay

Western blotting was performed using $20 \mu \mathrm{g}$ of plasma protein from each subject per lane in $8 \%$ SDS-PAGE gels under reducing conditions with 5\% 2-mercaptoethanol boiled for $10 \mathrm{~min}$. After electrophoresis, proteins were transferred to PVDF membranes and blocked with $2.5 \%$ nonfat dry milk in $100 \mathrm{mM}$ Tris-HCl buffer, pH 7.5 with $150 \mathrm{~mm} \mathrm{NaCl}$ and $0.1 \%$ Tween 20 (TTBS buffer) and incubated for $90 \mathrm{~min}$ with the following monoclonal antibodies: $2 \mu \mathrm{g} / \mathrm{ml}$ anti-MMP-2, $4 \mu \mathrm{g} / \mathrm{ml}$ anti-MMP-9, $10 \mu \mathrm{g} / \mathrm{ml}$ antiMT1-MMP, $2 \mu \mathrm{g} / \mathrm{ml}$ anti-TIMP-1 and $2 \mu \mathrm{g} / \mathrm{ml}$ anti-TIMP-2 (Calbiochem-Novabiochem International, San Diego, Calif., USA). Beta-tubulin (1:200) was used as loading control (CalbiochemNovabiochem International). Unbound antibodies were removed by washing with TTBS buffer. Primary antibodies were detected with the VectaStain ABC kit (Vector Laboratories, Burlingame, Calif., USA). Bands identified in the immunoblotting assay were analyzed by densitometry and results were expressed as DU.

\section{Statistical Analysis}

The $\chi^{2}$ test that combines the $2 \times 2$ contingency tables (EPIINFO statistical program, version $6.04 \mathrm{~b}$ ) was used to determine the association between the response to therapy and the risk factor. The $\chi^{2}$ were calculated using the Yates correction. Gelatinase activity and Western blot results were analyzed using the MannWhitney $U$ test and expressed as mean \pm standard error. For all results, $\mathrm{p} \leq 0.05$ was considered significant.

\section{Results}

\section{Lung Adenocarcinoma Incidence}

Most of the patients examined were never-smokers (69.2\%, 54 of 78 subjects) and $50 \%$ of them had been exposed to wood smoke (table 1). The highest WS was observed in women, while $\mathrm{T}$ was identified as the major risk factor in men. In the $\mathrm{N}$ group (27 patients), 63\% were women and $37 \%$ were men. Clinical staging demonstrated that most of the patients had stage IV of the disease (73.1\%).

\section{Chemotherapy Response}

The ORR for all lung cancer patients was 59\% (46 of 78 subjects) (table 2). According to the risk factor, there were significant differences in chemotherapy response between the WS and the T groups $(\mathrm{ORR}=26.9 \%$, i.e. 21 of 78 and $12.8 \%$, i.e. 10 of 78 patients, respectively; OR = $4.9,95 \% \mathrm{CI}=1.25-20.15 ; \mathrm{p}=0.019$; Yates-corrected) (table 2). The number of subjects with an ORR to treatment in the $\mathrm{N}$ group was close to the number of patients with a progression of the disease. The differences between them and the WS and T groups were therefore not significant, nor were those between the chemotherapy regimens and disease stages of the 3 groups.

\section{Plasma Gelatinase Activity}

Gelatinase activity was increased in all lung cancer patients compared to that in the control subjects $(36.8 \pm 4.8$ 
Table 2. Chemotherapy response according to stage and risk factor

\begin{tabular}{lrccr}
\hline Response & CR & PR & ORR & PD \\
\hline All Patients & 25.6 & 33.3 & 59 & 41 \\
Risk factor & & & & \\
$\quad$ WS & 16.7 & 10.3 & 26.9 & 7.7 \\
T & 2.6 & 10.3 & 12.8 & 17.9 \\
N & 6.4 & 12.8 & 19.2 & 15.4 \\
Stage (TNM) & & & & \\
$\quad$ IIIA & 3.8 & 0 & 3.8 & 2.7 \\
IIIB & 10.3 & 6.4 & 16.7 & 3.8 \\
IV & 11.5 & 26.9 & 38.5 & 34.6 \\
\hline
\end{tabular}

Data are expressed as $\%(100 \%=78$ patients $)$. Response to chemotherapy was evaluated according to RECIST: $\mathrm{CR}=$ complete response; $\mathrm{ORR}=$ overall response rate (i.e. $\mathrm{CR}+\mathrm{PR}$ ); $\mathrm{PD}=$ progression of disease; $\mathrm{PR}=$ partial response.

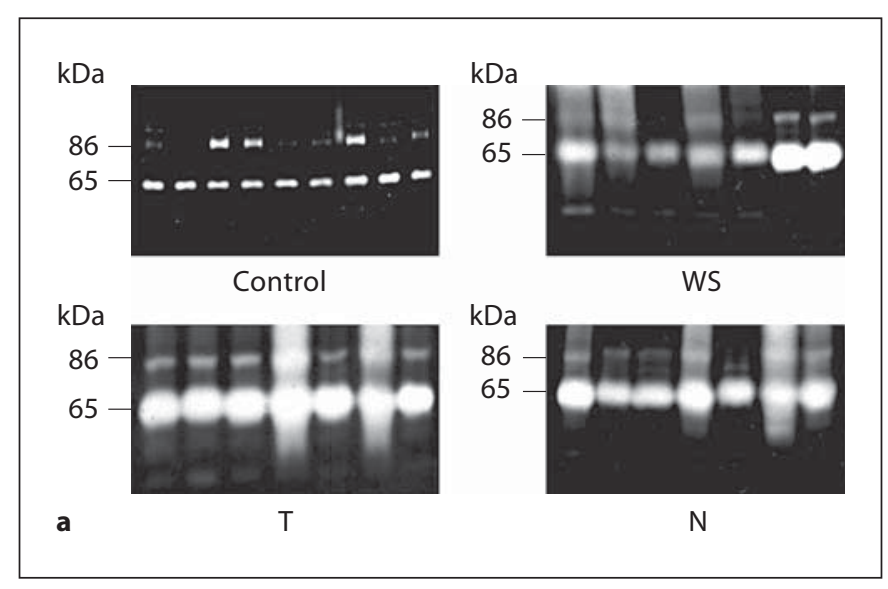

Fig. 2. Gelatin substrate zymography. a MMP-2 gelatinase activity (65-kDa band) was detected in all cancer samples, with an increase in its intensity in comparison with control subjects. MMP9 gelatinase activity ( $86-\mathrm{kDa}$ band) was also identified in most of the lung cancer subjects. Molecular weight markers are listed on

$\mu \mathrm{g}$ of degraded gelatin/mg of incubated plasma protein; $\mathrm{p}<0.001$ ) (fig. 1). Regarding the cancer groups, the lowest activity was observed in WS subjects, in comparison with the $\mathrm{T}$ and $\mathrm{N}$ groups $(96.7 \pm 15.9,182.9 \pm 31.5$ and 163.3 $\pm 22.7 \mu \mathrm{g}$ of degraded gelatin/mg of incubated plasma protein, respectively; $\mathrm{p}<0.025$ ).

Likewise, most of the patients with an ORR had low rates of gelatinase activity (38 of 46 patients) compared with subjects with PD (27 of 32 subjects) (60.6 \pm 4.5 and

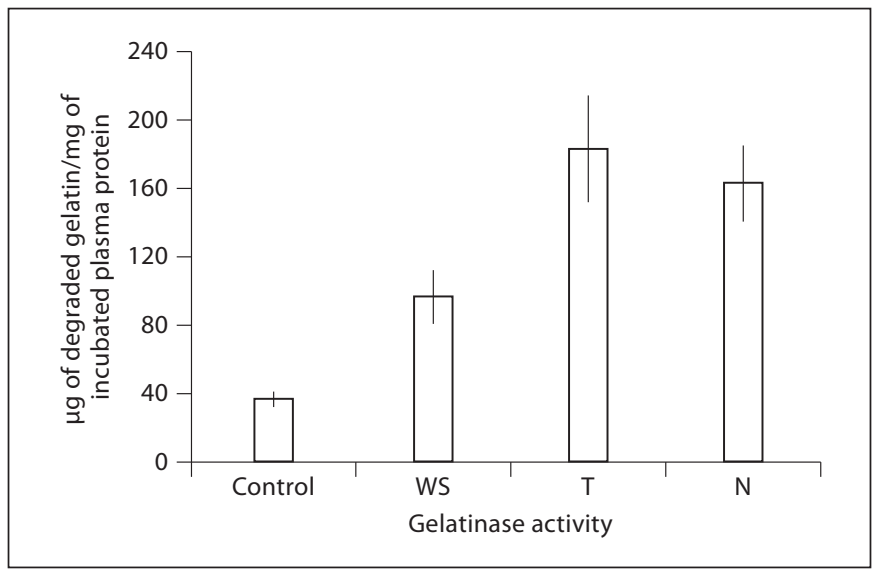

Fig. 1. Gelatinase activity. MMPs gelatinase activity was increased in all lung cancer patients in comparison with control subjects $(\mathrm{p}<0.001)$. Among risk groups, WS patients had the lowest gelatinase activity $(\mathrm{p}<0.025)$. Bars indicate the mean of each group \pm standard error.

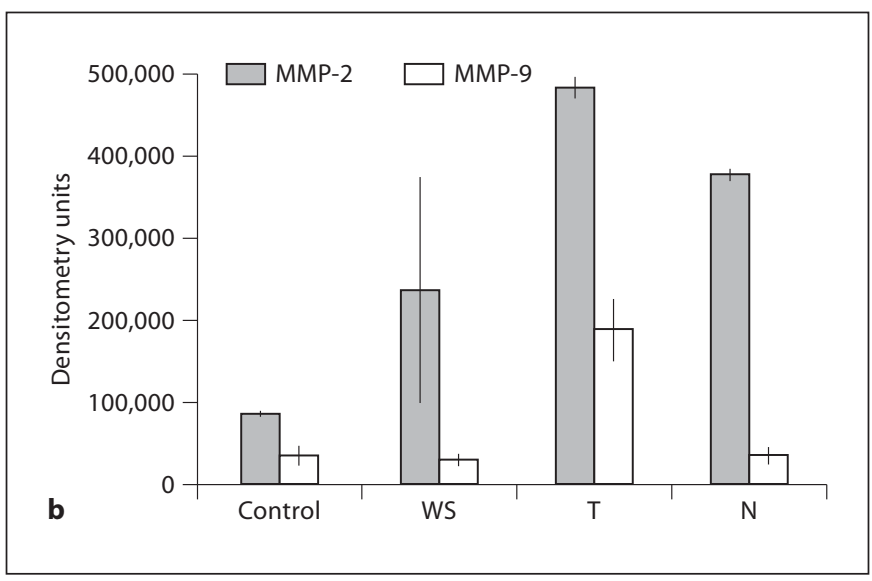

the left. b The zymography densitometry analysis showed an increase in MMP-2 intensity in the T group compared with the control, WS and N subjects ( $<<0.02)$. MMP-9 intensity was also increased in $\mathrm{T}$ patients in comparison with the other groups $(\mathrm{p}<$ $0.0045)$.

$288.5 \pm 22.8 \mu \mathrm{g}$ of degraded gelatin/mg of incubated plasma protein; $\mathrm{p}=4.73 \times 10^{-17}$ ). The $\chi^{2}$ test showed a correlation between ORRs and low gelatinase activity rates $(\mathrm{OR}=0.04,95 \% \mathrm{CI}=0.01-0.15 ; \mathrm{p}<0.000001$; Yatescorrected).

Zymography analysis revealed the presence of a lysis band of about $65 \mathrm{kDa}$ in all samples (fig. 2a). This band corresponded to MMP-2 activity. The highest intensity of this band was observed in the T group samples $(483,706.3$ 


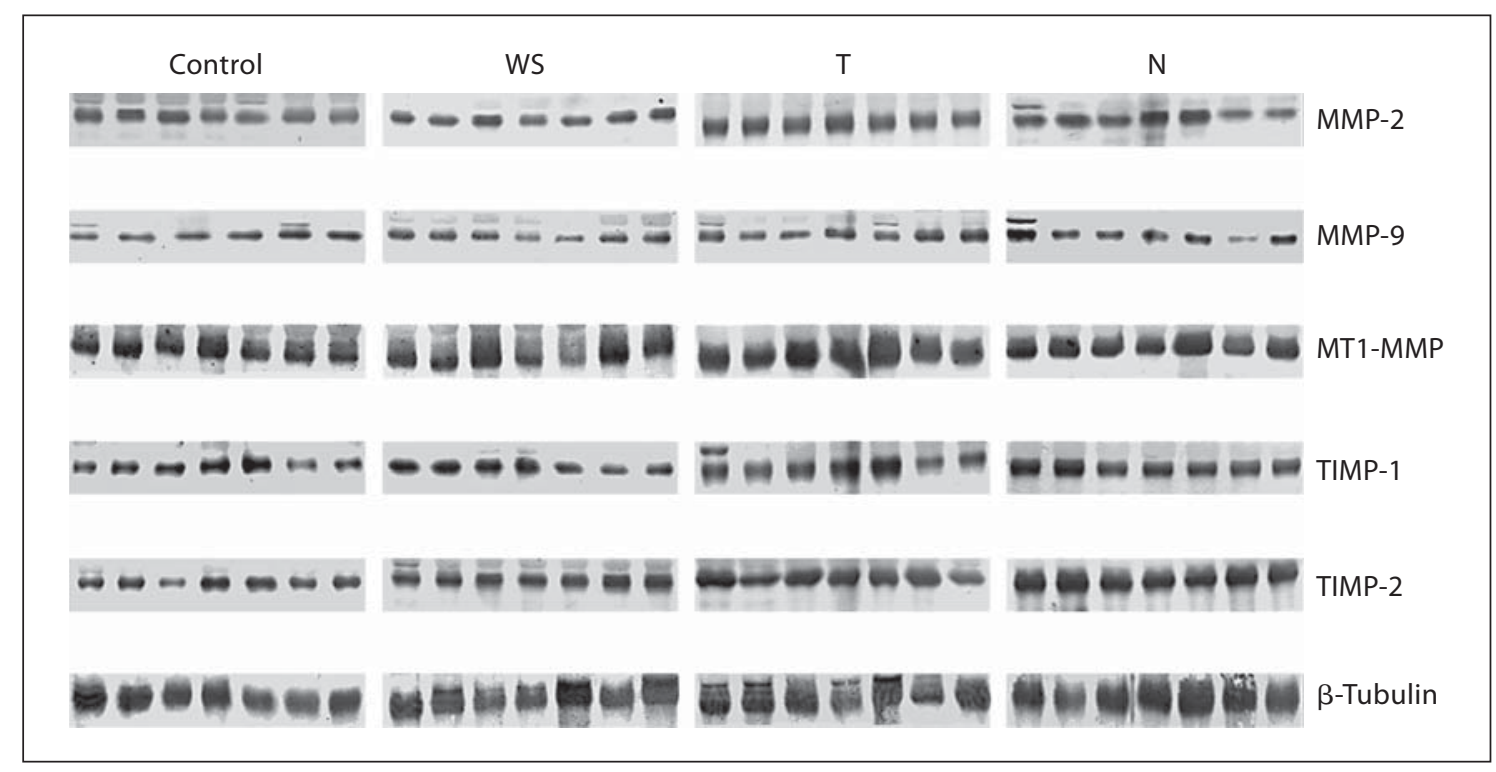

Fig. 3. MMP and TIMP Western blots from lung adenocarcinoma plasma samples. Western blot assay demonstrated the presence of the MMP-2 active form (65-kDa band) in all samples assayed. The pro-MMP-2 was also detected in some samples as a $72-\mathrm{kD}$ a band. The MMP-9 active form was observed in all samples as an $86-\mathrm{kDa}$ band. A 92-kDa band (pro-MMP-9) was also identified. The active MT1-MMP (55-kDa band) form was present in all samples assayed. TIMP immunoblotting revealed the presence of a 28 $\mathrm{kDa}$ band which corresponded to TIMP-1. A 21-kDa band, TIMP2 , was also observed in the control and lung cancer samples. $\pm 12,778.7 \mathrm{DU})$ compared to the $\mathrm{N}$ and WS subjects $(377,490.1 \pm 7,836.9$ and $236,960 \pm 52,135.3 \mathrm{DU}$, respectively; $\mathrm{p}<0.02$ ) (fig. 2b). MMP-2 activity in all lung cancer samples was higher than that observed in the control group $(86,309.3 \pm 3,888.1 \mathrm{DU} ; \mathrm{p}<0.005)$. An $86-\mathrm{kDa}$ band (MMP-9 activity) was also identified in some control samples and in almost all lung cancer patients. The highest intensity of this band was observed in samples from the T group $(189,531 \pm 38,573.1 \mathrm{DU})$ when compared with the control, WS and N subjects $(35,934.2 \pm$ $11,074.8,30,639.3 \pm 7,349.9$ and 35,867.4 $\pm 11,134.2 \mathrm{DU}$, respectively; $\mathrm{p}<0.0045)$.

\section{MMP-9 and MMP-2 Plasma Levels}

MMP-2 Western blot demonstrated the presence of a $65-\mathrm{kDa}$ band in all samples (fig. 3). This band corresponded to the active form of MMP-2. In some samples, a $72-\mathrm{kDa}$ band (pro-MMP-2) was observed. The MMP-2 densitometry analysis showed a significant increase in MMP-2 plasma levels in the $\mathrm{T}$ and $\mathrm{N}$ groups compared to the control subjects $(57,907.7 \pm 5,196.9,57,952.1 \pm$ 3,798.4 and 45,487.2 \pm 1,393.8 DU, respectively; $\mathrm{p}<$ 0.015 ) (fig. 4a). There were no significant differences between WS patients and control subjects or between the lung cancer groups. MMP-9 immunoblotting revealed the presence of the MMP-9 active form as an $86-\mathrm{kDa}$ band in all samples (fig. 3). A $92-\mathrm{kDa}$ band that corresponded to pro-MMP-9 was also observed in some of the control and lung cancer samples. The highest $86-\mathrm{kDa}-$ band net intensity was found in the $\mathrm{T}$ group samples when compared to the controls $(52,950.8 \pm 6,042.2$ and $24,733.3 \pm 2,457.1 \mathrm{DU}$, respectively; $\mathrm{p}=0.003$ ) (fig. $4 \mathrm{a}$ ). MMP-9 protein concentration was also increased in the WS and N samples $(33,410.7 \pm 3,057.9$ and 39,420.7 \pm $3,808.5 \mathrm{DU}$, respectively; $\mathrm{p}<0.04$ ) when compared to the control group. There were significant differences between the WS and T groups $(\mathrm{p}=0.005)$.

Regarding chemotherapy response there were no significant differences in MMP-2 and MMP-9 plasma levels among subjects with ORR and with PD.

\section{MT1-MMP Plasma Levels}

MT1-MMP immunoblotting technique demonstrated the presence of a band with a molecular weight of about $55 \mathrm{kDa}$ in most of the plasma samples (fig. 3). Densitometry analysis showed a significant increase of this MTMMP in samples from all lung cancer groups in comparison with control subjects $(38,068.4 \pm 2,935.2 \mathrm{DU}$; $\mathrm{p}<$ 0.003 ) (fig. 4a). The T group had the highest MT1-MMP plasma concentrations $(76,292.8 \pm 3,442.5 \mathrm{DU})$ in com- 


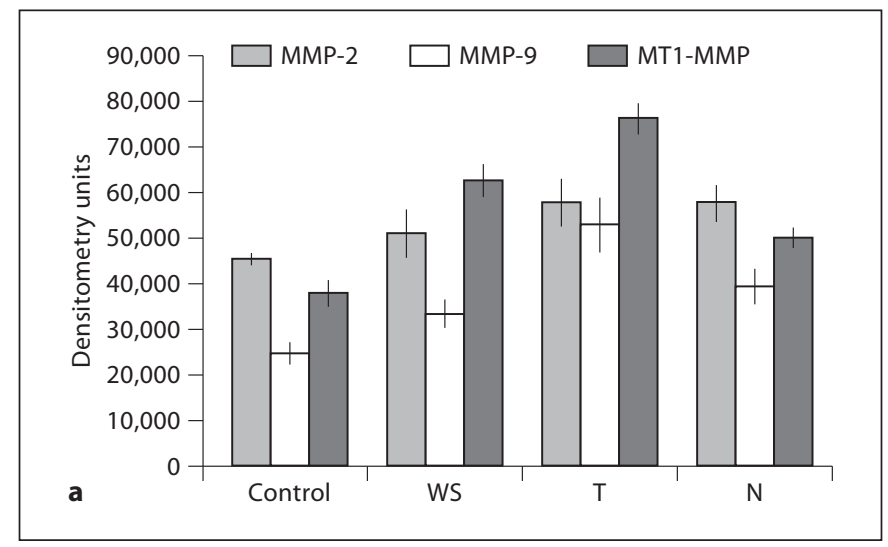

Fig. 4. Western blot densitometry analysis. a An increase of MMP-2 in plasma samples from the $\mathrm{T}$ and $\mathrm{N}$ groups $(\mathrm{p}<0.015)$ is shown. MMP-9 plasma levels were increased in all cancer samples in comparison with control subjects. MMP-9 concentration was higher in the T group in comparison with the WS samples ( $\mathrm{p}=$ 0.005). The analysis of the MT1-MMP bands showed that its highest plasma concentration corresponded to the $\mathrm{T}$ group and the

parison with the WS and the $\mathrm{N}$ groups $(62,710.4 \pm 3,527.9$ and 50,167.7 $\pm 2,226.4$ DU, respectively; $\mathrm{p}<0.015$ ).

Regarding the chemotherapy response, differences in plasma MT1-MMP levels among patients with ORR and with PD were not significant.

\section{TIMPs' Plasma Concentration}

In all groups, TIMP Western blot revealed a 21- and a 28-kDa band which corresponded to TIMP-2 and TIMP1 , respectively (fig. 3). There was a significant increase in TIMP-1 plasma concentration in lung cancer patients in comparison with the control group $(36,571.9 \pm 1,164.1$ DU; p < 0001) (fig. 4b). Although the highest net intensity of TIMP-1 was observed in the T group $(100,526.9 \pm$ $11,537.2 \mathrm{DU})$, there were no significant differences among this group and the WS $(74,580.6 \pm 7,403.8 \mathrm{DU})$ and $\mathrm{N}$ $(84,013.8 \pm 8,147.6 \mathrm{DU})$ lung cancer groups.

TIMP-2 protein levels were increased in all lung cancer groups when compared with control subjects $(57,028.5 \pm 1,798.2 \mathrm{DU} ; \mathrm{p}<0.0001)$ (fig. $4 \mathrm{~b})$. There was a significant increase of TIMP-2 plasma concentration in samples from the $\mathrm{N}$ group $(216,122.1 \pm 19,538.9 \mathrm{DU})$ in comparison with the WS and T patients $(166,419.3 \pm$ 8,212.9 and 152,756.1 $\pm 12,595.9 \mathrm{DU}$, respectively; $\mathrm{p}<$ $0.025)$.

Regarding the chemotherapy response and TIMPs' plasma concentration, differences among patients with ORR and with PD were not significant.

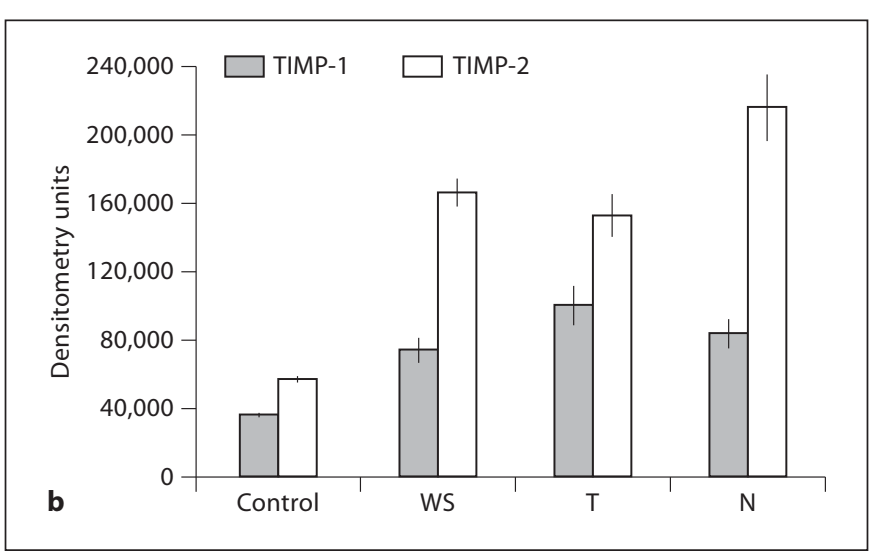

lowest to the WS patients. b An increase of plasma TIMP-1 levels in all lung cancer samples is shown, particularly in the T group $(\mathrm{p}<0.0001)$. TIMP-2 concentration was also increased in plasma samples from lung cancer patients in comparison with control subjects ( $\mathrm{p}<0.0001)$. The $\mathrm{N}$ group had the highest concentration in comparison with the other lung cancer groups $(p<0.025)$. Bars indicate the mean of each group \pm standard error.

\section{Discussion}

WS has been considered a risk factor for lung cancer in never-smokers; however, information about its molecular and clinical features is scarce [24].

In this study, we found that $69.2 \%$ of the analyzed primary lung adenocarcinoma patients were never-smokers. Lung cancer incidence was higher in women than in men, particularly in the never-smoker group; probably because this group included WS patients, and women are exposed to wood smoke for more hours than men $[6,8]$.

We also observed that never-smokers, particularly WS patients, had a better response to cisplatin first-line therapy. In this context, Toh et al. [19] found no differences in the response to cisplatin first-line chemotherapy among tobacco smokers and never-smokers. On the contrary, Tsao et al. [18] observed that never-smokers had higher response rates and lower PD rates than smokers. The differences in these studies could be due to the different ethnic populations analyzed (Asiatic and Caucasian, respectively). Regarding targeted therapy response, it has been described that never-smoker women with lung adenocarcinoma had a better response to erlotinib or gefitinib, both epidermal growth factor receptor inhibitors, when compared to smokers. The response to these drugs has been associated with mutations found in the tyrosine kinase domain of the epidermal growth factor receptor [25]. The response to cisplatin that we observed was per- 
haps also associated with this protein or to modifications in other molecules such as the multidrug-resistant gene 1 and the excision repair cross-complementing 1 protein; here, further research is necessary [26, 27].

Likewise, it is possible that the expression and activity of other proteins such as MMPs and TIMPs could be different among tobacco smokers and never-smoker lung cancer patients. Regarding these molecules, it has been pointed out that the metastatic potential of a neoplastic cell is associated with an increase in MMP expression and enzymatic activity [11, 12]. Therefore, these enzymes have been studied in many cancers looking for the possibility of a reliable prognostic factor. However, disagreement still prevails as to which MMPs are more sensitive to predict non-small-cell lung cancer progression. In this context, some authors found an association between a poor prognosis and an increase in MMP-9 tissue expression with a TIMP-1 decrease in the early stages of the disease, while others suggested that the increase in MMP-2 synthesis is a better prognostic biomarker than MMP-9 [28-30].

In our study, we analyzed the plasma concentration and gelatinase activity of MMP-2 and MMP-9. We found that the plasma enzymatic activity of these molecules was increased in lung cancer patients in comparison with control subjects, particularly in those patients with PD. Moreover, we observed a correlation between chemotherapy response and gelatinase activity but not between the plasma concentrations of MMPs and of TIMPs.

Likewise, gelatinase activity was significantly lower in the WS group in comparison with the $\mathrm{T}$ patients. Interestingly, the WS group showed the best response to chemotherapy, while the $\mathrm{T}$ group had the highest $\mathrm{PD}$ rates. Regarding the $\mathrm{N}$ group, even though plasma samples from this group showed higher gelatinase activity in comparison with WS subjects, a correlation with chemotherapy response was hard to make, because too large a variation was observed in the treatment response. This variation could be due to the undefined risk factors involved in the pathogenesis of lung cancer among these subjects.

The zymography analysis demonstrated an increase in the MMP-2 enzymatic activity in all lung cancer patients in comparison with control subjects. However, MMP-2 blood concentration was similar in the WS and control groups. On the other hand, TIMP-2 concentration was increased in cancer samples. Besides TIMP-2 inhibitory activity, this protein is able to activate proMMP-2, forming a molecular complex with MT1-MMP (MMP-14) on the cell surface [31]. Therefore, the MMP-2 activity found

MMPs in Wood Smoke Lung Cancer Patients in lung cancer patients is probably due to the activation process of this enzyme. Moreover, we also measured the other component of the activation complex, the MT1MMP. This MMP was also increased in lung cancer patients, particularly in the T group. In this group, the increase in both MT1-MMP and MMP-2 could explain, at least in part, the high MMP-2 gelatinase activity found in the $\mathrm{T}$ patients.

Likewise, MMP-9 activity detected by zymography was increased in some patients when compared to the control group, but it was lower than MMP-2 enzymatic activity. Its plasma concentration was also lower than MMP-2. TIMP-1 concentration was also increased, and this TIMP has the function to activate proMMP-9 through the formation of a complex with MMP-3, as does TIMP-2 [32]. Therefore, the high MMP-9 and TIMP-1 levels together with the MMP-2 enzymatic activity observed in the $\mathrm{T}$ group could explain the high gelatinase activity found in these patients.

In summary, our results point out that there are differences in the metastatic profile and in the cisplatin firstline chemotherapy response between patients with tobacco-induced and those with wood-smoke-induced lung cancer. This implies that treatments for these 2 groups must be different. Tobacco smokers with an increase in MMP plasma concentration and in plasma gelatinase activity should receive - alone or in combination with the conventional chemotherapy - a specific therapy that interferes with MMP synthesis and activation $[33,34]$. Furthermore, first-line treatment with a cisplatin base could be a good option for WS patients with low MMP plasma levels and gelatinase activity, when targeted therapy becomes unaffordable. On the other hand, predictive indexes for the second- and third-line therapy of nonsmall-cell lung cancer have been developed $[35,36]$. According to our results, quantification of MMP-2, MMP-9, MT1-MMP, TIMP-1 and TIMP-2 plasma levels, as well as MMP-2 and MMP-9 gelatinase activity, could be used as a reliable indicator of the metastatic potential and, consequently, greatly improve predictive prognostic indexes.

Finally, as Maio [37] points out, it is difficult for a physician to choose a therapy based on affordability; however, the physician must offer each patient the most effective treatment.

\section{Acknowledgement}

This work was supported by a grant from CONACYT (SALUD2003-C01-8). 


\section{References}

1 Parkin DM, Bray F, Ferlay J, Prisani P: Global cancer statistics, 2002. CA Cancer J Clin 2005;55:74-108.

$>2$ Subramanian J, Govindan R: Lung cancer in never smokers: a review. J Clin Oncol 2007; 25:561-570.

$\checkmark 3$ Rudin ChM, Avila-Tang E, Harris CC, Herman JG, Hirsh FR, Pao W, Schwartz AG, Vahakangas KH, Samet JM: Lung cancer in never smokers: molecular profiles and therapeutic implications. Clin Cancer Res 2009; 15:5646-5661.

4 Fullerton DG, Bruce N, Gordon SB: Indoor air pollution from biomass fuel smoke is a major health concern in the developing world. Trans R Soc Trop Med Hyg 2008;102: 843-851.

5 Lissowska J, Bardin-Mikolajczak A, Fletcher T, Zaridze D, Szeszenia-Dabrowska N, Rudnai P, Fabianova E, Cassidy A, Mates D, Hoicatova I, Vitova V, Janout V, Manneje A, Brennan P, Boffeta P: Lung cancer and indoor pollution from heating and cooking with solid fuels. The IARC International Multicentre Case-Control Study in eastern/ central Europe and the UK. Am J Epidemiol 2005;162:326-333.

6 Delgado J, Martínez LM, Sanchez TT, Ramirez A, Iturria C, Gonzalez-Avila G: Lung cancer pathogenesis associated with wood smoke exposure. Chest 2005;128:124131.

7 Straif K, Baan R, Grosse Y, Secretan B, El Ghissassi F, Cogliano V, WHO International Agency for Research on Cancer Monograph Working Group: Carcinogenicity of household solid fuel combustion and of high-temperature frying. Lancet Oncol 2006;7:977978.

$>8$ Torres-Duque C, Maldonado D, Perez-Padilla R, Ezzati M, Viegi G, Forum of International Respiratory Studies (FIRS) Task Force on Health: Effects of biomass exposure: biomass fuels and respiratory diseases. A review of the evidence. Proc Am Thoracic Soc 2008; 5:577-590.

-9 Scagliotti GV, Longo M, Novello S: Nonsmall cell lung cancer in never smokers. Curr Opin Oncol 2009;21:99-104.

-10 Toh CK, Gao F, Lim WT, Leong SS, Fong KW, Yap SP, Hsu AAL, Eng Ph, Koong HN, Thirugnanam A, Tan EH: Never-smokers with lung cancer: epidemiologic evidence of a distinct disease entity. J Clin Oncol 2006; 24:2245-2251.

-11 Deryugina EI, Quigley JP: Matrix metalloproteinases and tumor metastasis. Cancer Metastasis Rev 2006;25:9-34.

12 Duffy MJ, McGowan PM, Gallagher WM: Cancer invasion and metastasis: changing views. J Pathol 2008;214:283-293.
13 Murphy G, Nagase H: Progress in matrix metalloproteinases research. Mol Aspects Med 2008;29:290-308.

14 Brew K, Nagase H: The tissue inhibitors of metalloproteinases (TIMPs): an ancient family with structural and functional diversity. Biochim Biophys Acta 2010;1803.55-71.

15 Adizzoni A, Boni L, Tiseo M, Fossella FV, Schiller JH, Paesmans M, Radosavijevic D, Paccagnella A, Zatioukai P, Mazzanti P, Bisset D, Rosell R: Cisplatin- versus carboplatin-based chemotherapy in first-line treatment of advanced non-small-cell lung cancer: an individual patient data meta-analysis. J Natl Cancer Inst 2007;99:847-857.

16 Hanna N, Shepherd FA, Fossella FV, Preira JR, De Marinis F, von Pawel J, Gatzameier U, Tsao TC, Pless M, Muller T, Lim HL, Desch C, Szondy K, Gervais R, Shaharyar, Manegold C, Paul S, Paoletti P, Einhorn L, Bunn PA Jr: Randomized phase III trial of pemetrexed versus docetaxel in patients with nonsmall-cell lung cancer previously treated with chemotherapy. J Clin Oncol 2004;22: 1589-1597.

17 Lee YJ, Kim JH, Kim SK, Ha SJ, Mok TS, Mitsudomi T, Cho BC: Lung cancer in never smokers: change of a mindset in the molecular era. Lung Cancer 2011;72:9-15.

18 Tsao AS, Liu D, Lee JJ, Spitz M, Hong WK: Smoking affects treatment outcome in patients with advanced nonsmall cell lung cancer. Cancer 2006;106:2428-2436.

19 Toh CK, Wong EH, Lim WT, Leong SS, Fong KW, Wee J, Tan EH: The impact of smoking status on the behavior and survival outcome of patients with advanced non-small cell lung cancer. A retrospective analysis. Chest 2004;126:1750-1756.

20 Mountain CF: Revisions in the international system for staging lung cancer. Chest 1997; 111:1710-1717.

21 Therasse P, Arbuck SG, Eisenhauer EA, Wanders J, Kaplan RS, Rubinstein L, Verweij J, van Glabbeke M, van Oosterom AT, Christian MC, Gwyther SG: New guidelines to evaluate the response to treatment in solid tumors. J Natl Cancer Inst 2000;92:205-216.

-22 Smith PK, Krohn RI, Hermanson GT, Mallia AK, Gartner FH, Provenzano MD, Fujimoto EK, Boeke NM, Olson BJ, Klenk DC: Measurement of protein using bicinchoninic acid. Anal Biochem 1985;150:76-85.

23 Sunada H, Nagai Y: A rapid microassay method for gelatinolytic activity using tritium-labeled heat-denatured polymeric collagen as a substrate and its application to the detection of enzymes involved in collagen metabolism. J Biochem 1980;87:1765-1772.

24 Lim WY, Seow A: Biomass fuels and lung cancer. Respirology 2012;17:20-31.

-25 Gerber DE: EGFR inhibition in the treatment of non-small cell lung cancer. Drug Dev Res 2008;69:359-372.
26 Pan JH, Han JX, Wu JM, Huang HN, Yu QZ, Sheng LJ: MDR1 single nucleotide polymorphism G2677T/A and haplotype are correlated with response to docetaxel-cisplatin chemotherapy in patients with non-smallcell lung cancer. Respiration 2009;78:49-55.

27 Rabik CA, Dolan ME: Molecular mechanisms of resistance and toxicity associated with platinating agents. Cancer Treat Rev 2007;33:9-23.

28 Sienel W, Hellers J, Morresh-Hauf A, Lichtinghagen R, Mutschler W, Jochum M, Klein C, Passlick B, Pantel K: Prognostic impact of matrix metalloproteinase-9 in operable nonsmall cell lung cancer. Int J Cancer 2003;103: 647-651.

29 Inesta P, Moran A, De Juan C, Gomez A, Hernando F, Garcia-Aranda C, Frias C, Diaz-Lopez A, Rodriguez-Jimenez FJ, Balibrea JL, Benito M: Biological and clinical significance of MMP-2, MMP-9, TIMP-1 and TIMP-2 in non-small cell lung cancer. Oncol Rep 2007;17:217-223.

30 Guo CB, Wang S, Deng C, Zhang DL, Wang FL, Jin XQ: Relationship between matrix metalloproteinase 2 and lung cancer progression. Mol Diag Ther 2007;11:183-192.

31 Strongin AY: Proteolytic and non-proteolytic roles of membrane type-1 matrix metalloproteinase in malignancy. Biochim Biophys Acta 2010;1803:133-141.

32 Woessner JR, Nagase H (eds): Activation of zymogen forms of MMPs; in: Matrix Metalloproteinases and TIMPs. New York, Oxford University Press, 2000, pp 72-76.

33 Chetty C, Bhoopathi P, Joseph P, Chittivelu S, Rao JS, Lakka S: Adenovirus-mediated small interfering RNA against matrix metalloproteinase-2 suppresses tumor growth and lung metastasis in mice. Mol Cancer Ther 2006;5:2289-2299.

34 Amalinei C, Caruntu ID, Giusca SE, Balan RA: Matrix metalloproteinases involvement in pathological conditions. Rom J Morphol Enbryol 2010;51:215-228.

-35 Wojas-Krawczyk K, Krawczyk P, Mlak R, Kucharczyk T, Kowalski DM, Krzakowski M, Milanowski J: The applicability of a predictive index for second- and third-line treatment of unselected non-small-cell lung cancer patients. Respiration 2011;82:341350 .

-36 Florescu M, Hasan B, Seymour L, Ding K, Shepherd FA, National Cancer Institute of Canada Clinical Trials Group: A clinical prognostic index for patients treated with erlotinib in National Cancer Institute of Canada Clinical Trials Group study BR.21. J Thorac Oncol 2008;3:590-598.

37 Maio G: Can help for patients be too expensive? Ethical considerations and end-stage lung disease. Respiration 2011;82:395-399. 